\title{
Numerical study of the behaviour of loop bar splicing in joints of reinforced concrete structures
}

\section{Estudo numérico do comportamento de emendas de barras por meio de laço em juntas de estruturas de concreto armado}
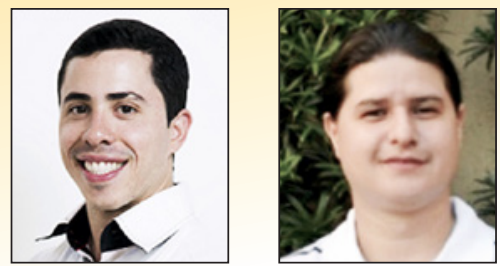

\author{
T. D. L.VASCONCELOS \\ thiagodelfino@usp.br \\ https://orcid.org/0000-0003-1212-6893 \\ V. G. HAACH a \\ vghaach@sc.usp.br \\ https://orcid.org/0000-0002-9501-4450
}

\begin{abstract}
Sometimes straight bar splicing takes up too much space in a reinforced concrete structure due to the required overlapping length. Therefore, in limited space situations, loop joints may be a good solution, which has been spread in civil construction, although there are very few studies about it. The aim of the present work is to study the loop joint behavior in reinforced concrete structures under tension. Three dimensional numerical simulations are made using the software DIANA $B$. Firstly, the calibration of the numerical model based on experimental tests of the literature is performed, followed by parametric analyses varying geometric parameters of the concrete elements and reinforcement. The results indicate that arranging the bars as close as possible to a maximum spacing of $60 \mathrm{~mm}$ between axes and considering a minimum splice length equal to the bend diameter of the loops may be an ideal situation for the behavior of this type of connection.
\end{abstract}

Keywords: loop joint, splicing, reinforced concrete, numerical simulation.

\section{Resumo}

Emendas com barras retas ocupam muito espaço devido ao comprimento de traspasse necessário. Dessa forma, em situações em que há uma limitação de espaço para a emenda, uma armação que constitui uma solução interessante é a emenda por meio de laço, que, apesar de ter poucos estudos relacionados, vem sendo bastante difundida na construção civil. O objetivo desse trabalho é estudar o comportamento de emendas em laço em juntas de estruturas de concreto armado submetidas à tração. Para isso, realizam-se simulações numéricas no software DIANA $®$ em modelos numéricos 3D. Inicialmente se faz a calibração do modelo numérico com base em ensaios experimentais da literatura, depois é realizada uma análise paramétrica variando parâmetros geométricos das peças e da armação em laço. Os resultados indicam que dispor as barras o mais próximo possível até um espaçamento máximo de $60 \mathrm{~mm}$ entre eixos e considerar um traspasse mínimo igual ao diâmetro de dobra dos laços pode ser uma situação ideal para o comportamento deste tipo de ligação.

Palavras-chave: junta, emenda, laço, concreto armado, simulação numérica. 


\section{1. 'Introduction}

In constructions, when it is necessary to provide continuity to structure, it is usual the appearance of joints, indispensable for linking the structural elements of reinforced concrete, which can be precast or cast-in-place. Therefore, the structure performance as a monolithic element depends on the joints efficiency. So, it is necessary to provide an appropriate adhesion between the concrete interfaces and an overlapping between the elements that ensures the efforts transmission between them, ensuring a monolithic element.

For the overlappings, straight bars or bended bars are used. Between these last ones, there are the loop bars, which has spread in civil construction, mainly in precast constructions and bridges. The loop joint consists of bars bended in $180^{\circ}$, forming a $U$, spaced to ensure the efforts transmission between the loops (see Figure 1). Bruggeling e Huyge [6] recommended the maximum value of 4 times the bar diameter for the spacing between loops.

This kind of overlapping is appropriate for situations where the available space is insufficient for the overlapping length of straight bars, also when it is necessary to reduce the space occupied by the bars of the overlapping and this way, the interference in the construction process. In straight bars overlapping, the efforts transmission is made by the adhesion between the bar and concrete. On the other hand, in loop joints, in addition to transmission the efforts by adhesion, along the straight part of the bar, also arise radial efforts to the loop (Figure 2), transmitting stress for the concrete by radial compression [2].

Futhermore, the loop joint can have transversal bars to the loop plane, in order to reduce the tendency of separation from the concrete by splitting, ensuring that the failure occurs by bar yielding. Most studies about loop joint is experimental, limited to the evaluation of few test parameters when compared with numerical studies. These studies are divided into two main groups according to the effort studied: bending and tension. In the bending part, Dragosavic et al. [11] propose a formulation to estimate the load capacity of the joints. In this context, Rosenthal and Shimoni [19] analyzed splices

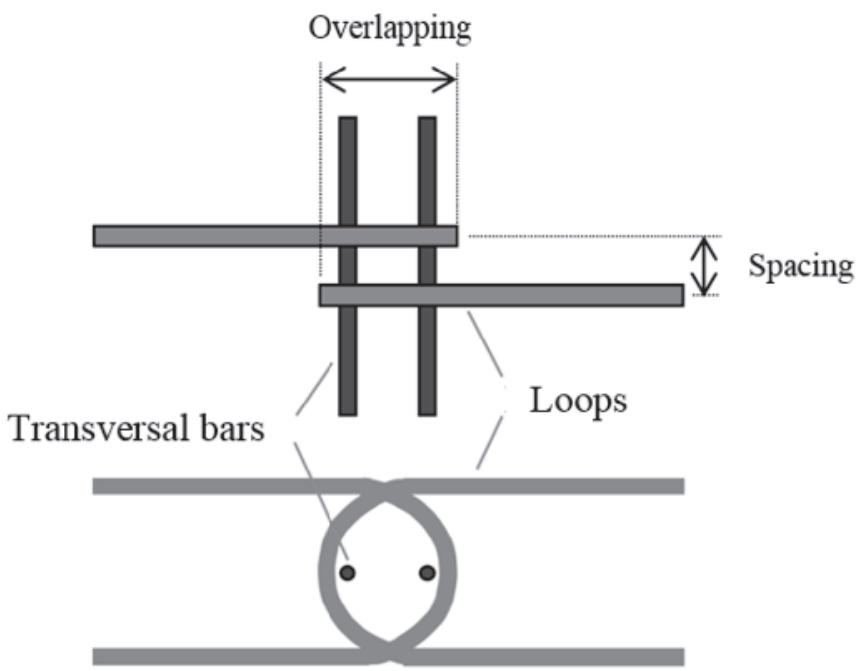

Figure 1

Constructive details of the loop:

top view (top) and lateral view (bottom) with the addition of an auxiliary stirrup, promoting the transfer between the loops. Therefore, these authors concluded that for a better performance of the structure, the overlapping on the auxiliary stirrup bar must be made in the compressed region of the element, as well as an epoxy compound should be applied on the interface of the joint before concreting it, in order to reduce cracking in that region. Hao [13] studied splicings with the loops positioned horizontally and vertically, besides being one of the few works in which the author implements a numerical model in order to estimate the cracking and loading capacity of the tested joints. These authors also carried out tests varying the method of application of roughness on the joint interface, concluding that the best method is sandblasting; same result obtained by Júlio et al. [16]. According to Hao [13], the smaller the distance between loops and the larger the transverse and longitudinal overlappings, the greater the resistance of the structure. In addition, the larger the bending diameter of the loop, the smaller the cracking moment and the higher the resistance of the joint, with this last property being also increased with the use of a higher rate of transverse reinforcement. Villalba et al. [25] performed tests with repeated loads to simulate traffic conditions on bridges, analyzing fatigue. With the results obtained, the authors proposed a formulation for the anchorage length of the loop and recommended to use transverse reinforcements to the loops.

The first researchers to study loop joints under tension were Leonhardt et al. [17], which performed tests on splicing without transverse bar, nonetheless, they emphasized the importance of using transverse bars in the control of cracking due to the tendency of separation between the loop and the concrete. Joergensen and Hoang [15] carried out experiments whose joint rupture is governed by the failure of the concrete present between the loops, concluding that the tensile strength of the splicing grows with the increase of transverse reinforcement rate, with the increase of longitudinal overlapping and with the decrease of the spacing between these bars. Araújo et al. [2] performed the same tests of the previous authors, differentiating only the model used, analyzing the use of steel fibers in the concrete of the joint. In this way, the addition of fibers increases the joint strength and helps to control its cracking. Joergensen and Hoang [15] and Araújo et al. [2] also proposed analytical models to estimate the load capacity of loop joints based on experimental test results. The difference between both models is that the first one is based on the principle of minimum energy and the second one is based on the strut and tie model, which also served as basis to the formulation proposed by Hao [13] for loop joints under tension. Based on a database created through tests, this author proposes analytical models to estimate the loading of cracks opening in the joint and the load capacity of it. Besides these

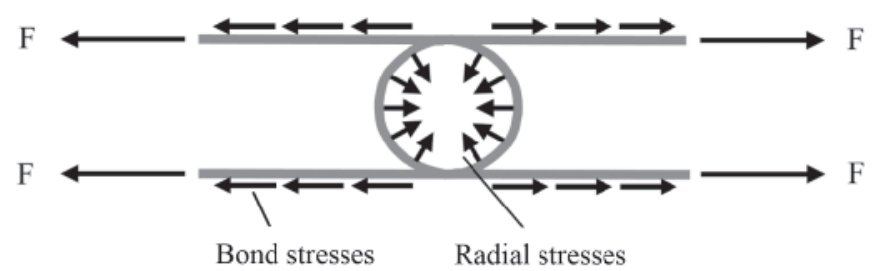

Figure 2

Compression radial stresses 
researches, there is the work of Vasconcelos [22], which performs parametric analyzes on numerical models varying the spacing and the overlapping between loops and based on the results obtained, makes suggestions of design values for both parameters. Mattock [18] also studies bars anchoring by means of loop and develops formulations to estimate its resistance, concluding that the larger the loop bars diameter, the greater the resistance of the splicing. Normative codes, such as Eurocode 2: 1992 [12], CEB-FIP 1990 [7], CEB-FIP2010 [8], BS 8110: 1997 [5], ABNT NBR 9062: 2006 [4] and ABNT NBR $6118: 2014$ [3], while contemplating the use of loop joints as a means of transmitting stresses between precast elements, do not present enough information, such as formulations for predicting the load capacity of the element. These codes only present recommendations for the minimum loop bending diameter and a formulation to obtain the bond stress on the bar.

The aim of the present work is to study the loop joint behavior in reinforced concrete structures under tension, by means of numerical simulations.

\section{Methodology}

In a first instant, some data were collected from experimental results obtained in the literature studied with the objective of creating a database to evaluate analytical models. Thus, numerical models were developed using DIANA® software. The calibration of the numerical model was performed by varying concrete parameters not present in the work of Joergensen and Hoang [15], work of reference, as the modulus of elasticity, tensile strength, tensile and compressive fracture energy, cracking bandwidth, the compressive strength reduction due to the cracking and the average diameter of the aggregates. To obtain these parameters, CEB 2010 [8] and 1990 [7] and the work of Hilsdorf and Brameshuber [14] were used. With the calibrated models, parametric studies were performed in the DIANA® software, varying the following parameters of the splicing geometry: overlapping length and spacing between loops. After that, the results of the parametric analysis were compared to the values obtained through the analytical models of the literature.

\section{Development}

The numerical models developed in this paper were calibrated based on the tensile tests performed by Joergensen and Hoang [15], see Figure 3. These authors carried out tensile tests on elements constituted by 3 blocks of reinforced concrete: the end blocks served only to provide stiffness to the structure to facilitate the test, since the central block contained the loop joint. The bars of the loops extended beyond the end blocks, where the authors imposed progressive displacements on the bars of one side and crimping on the others. The parameters varied by Joergensen and Hoang [15] were: the thickness of the concreting joint, the length of the joint, the distance between the loops, the loops overlapping length, the transverse bars diameter, the loop bars diameter, the yield stress of the transverse reinforcement and the yield stress of the loop bars.

In this work, the authors presented only the compressive strength of the concrete, $38.4 \mathrm{MPa}$, and the maximum diameter of the aggregates, $8 \mathrm{~mm}$, so it was necessary to calculate the other param-

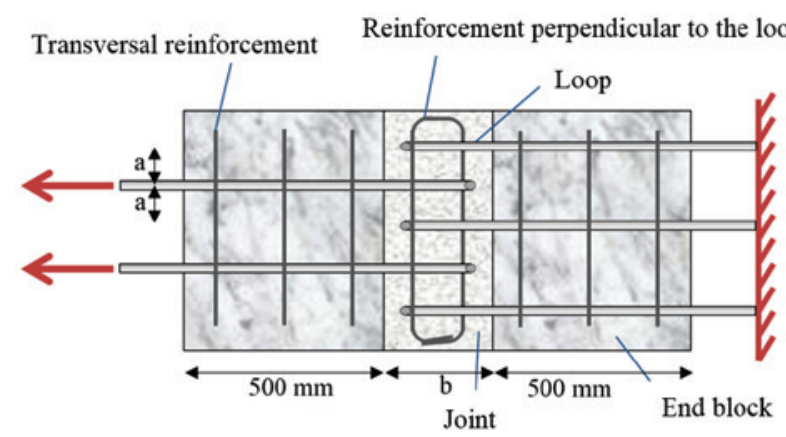

Figure 3

Tensile test studied

eters of the concrete only based on this information. In this way, the results obtained with the parameters calculated by CEB 2010 [8] will be presented and when explicit, for some of the parameters used, the calculations were also made by CEB 1990 [7] and based on the work of Hilsdorf and Brameshuber [14].

\subsection{Mesh}

For the concrete modelling, solid elements of the type $\mathrm{CHX60}$, of twenty nodes and quadratic approximation, were used. For the reinforcement, beam elements of type L13BE with two nodes were used. Both elements are in the DIANA® 9.5 program library [10]. The average processing time of one model was 3.5 days.

For the modelling of the block, solid elements with equal sides and length of $10 \mathrm{~mm}$ were used. From the concrete mesh, the beam elements were divided in order to match all their nodes with the solid element nodes of the concrete. Thus, the curved portions of the reinforcement, such as the loop curve, were represented by several straight beam elements.

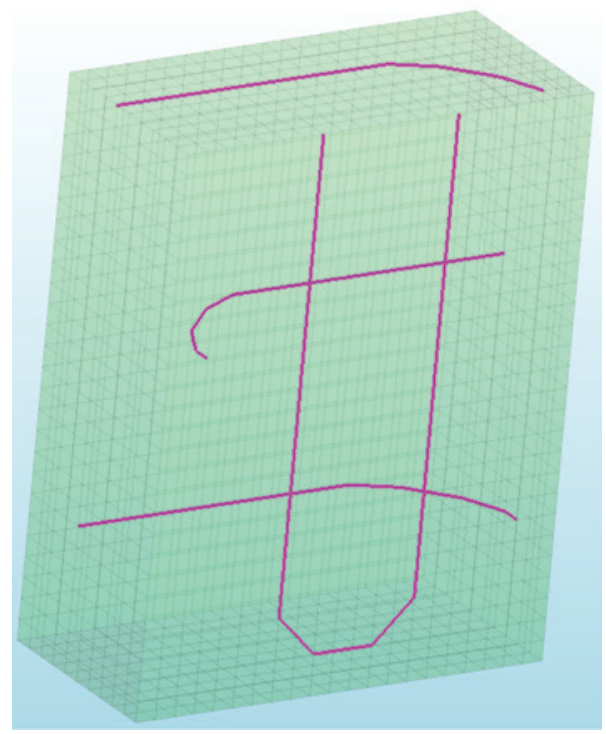

Figure 4

Mesh with reinforcement 


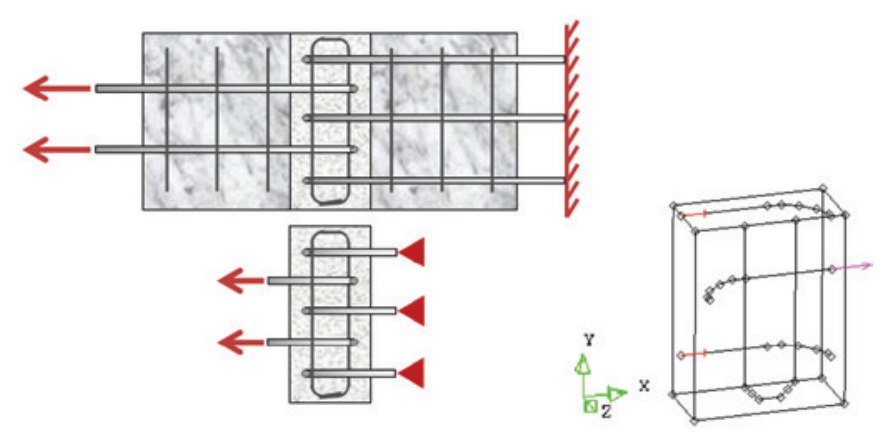

\section{Figure 5}

Representation of the boundary conditions in the experiment (left/top) and in numerical model (left/bottom and right)

In order to reduce even more the time of the simulations, it was taken advantage of the double symmetry of the problem, as well as modelling only the concrete joint of the element tested by Joergensen and Hoang [15] (see Figure 4).

\subsection{Loading and boundary conditions}

In the experimental tensile test carried out by Joergensen and Hoang [15], a displacement was applied on the bars of the side containing the least amount of loops, while the bars of the opposite side were crimped. In the proposed model of the present work, a displacement on X-axis was applied on the end of the single loop and it was restricted the displacement of the ends of the opposite loops on the same direction.

The elements used in the experiments of the aforementioned authors are composed of 3 concrete blocks: the joint block and the other two end blocks. Between the blocks, the interfaces were treated in such a way that there was minimal adherence, in this context, it could be disregarded the restriction to the joint translation on the plane of the blocks interface due to the contact between

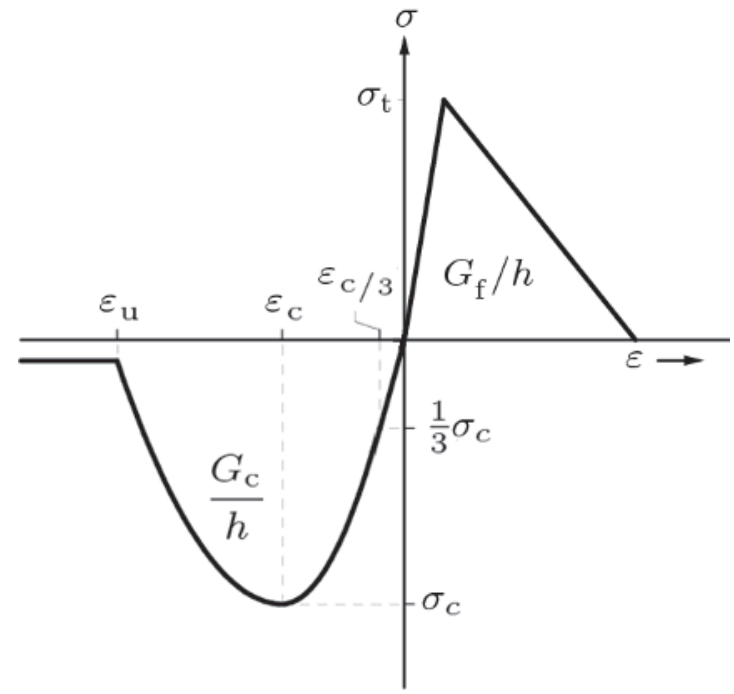

Figure 6

Concrete behavior them. Thus, the degrees of freedom of translation on this plane are only restricted by the pin effect of the loops bars.

Finally, due to the consideration of the double symmetry in the model, constraints of $Z$ translation of the symmetry surface of the $X Y$ plane and constraints of translation in $Y$ of the symmetry surface of the $X Z$ plane were also imposed. The Figure 5 illustrates the boundary and loading conditions of the problem. In order to solve the nonlinear equations system, the linear stiffness method was used, besides using the criterion of convergence in energy with a tolerance of $10^{-13}$.

\subsection{Concrete parameters}

The concrete was modelled with the Total Strain Fixed Crack Model, available in DIANA® 9.5 software [9]. In the Fixed Crack Model, the directions of the cracks are fixed and defined from the opening of the first cracks in each node of the elements, which are the directions of the principal stresses. In this way, when the failure criterion is reached, the directions and positions of the cracks are stored and used in subsequent load increments. This model of cracking was developed based on Compression Modified Field Theory, proposed by Vecchio and Collins [23].

For all analyses, the Poisson coefficient was considered constant and equal to 0.2 , even after cracking of the concrete.

The reduction of the tensile stress normal to the plane of the crack does not take place at once, it is progressive with the increase of the deformations, in this way, the concrete behavior in tensile in uniaxial state was adopted with linear reduction. In addition, the modulus of elasticity adopted in tensile was the same as in compression, as shown in Figure 6.

The fracture energy in tensile is defined as the energy required to propagate the tensile crack to an unit of area [14], which can be estimated as follows:

According to CEB 2010 [8], there is the Equation 1:

$G_{f}=73 f_{c}^{0,18}\left(\mathrm{Nm} / \mathrm{m}^{2}\right)$

According to CEB 1990 [7], there is the Equation 2:

$G_{f}=G_{f 0}\left(\frac{f_{c}}{10}\right)^{0,7}\left(\mathrm{Nm} / \mathrm{m}^{2}\right)$

According to Hilsdorf e Brameshuber [14], there is the Equation 3:

$G_{f}=a_{d} f_{c}^{0,7}\left(\mathrm{Nm} / \mathrm{m}^{2}\right)$

Where $G_{f o}$ is the base value of the fracture energy and $a_{d}$ is an adjustment coefficient of the function, which depends on the maximum diameter of the aggregates, whose values are given in Table 1. The cracking bandwidth can be calculated according to Equation 4 below:

$h=\frac{2 G_{f}}{\varepsilon_{c u} f_{t}}$.

Table 1

Values of $G_{f_{0}}$ and $a_{d}$

\begin{tabular}{ccc}
\hline $\mathbf{d}_{\max }(\mathrm{mm})$ & $\mathbf{G}_{\mathrm{fo}}\left(\mathrm{N}_{\mathrm{m}} / \mathbf{m}^{2}\right)$ & $\mathbf{a}_{\mathrm{d}}$ \\
\hline 8 & 25 & 4 \\
16 & 30 & 6 \\
32 & 58 & 10 \\
\hline
\end{tabular}




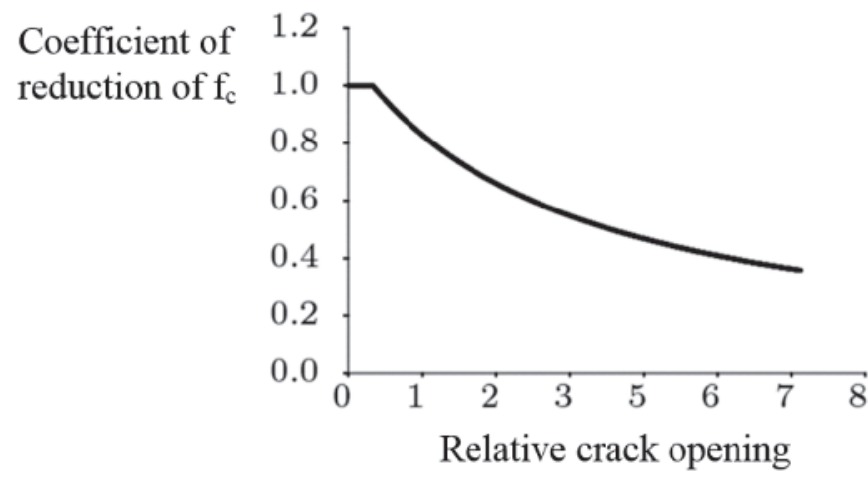

\section{Figure 7}

Model of lateral reduction proposed

by Vecchio and Collins (1993)

Where $\varepsilon_{\mathrm{cu}}$ is the ultimate concrete deformation in tensile and $\mathrm{f}_{-} \mathrm{t}$ is the concrete tensile strength. Considering $\varepsilon_{\mathrm{cu}}$ as the deformation on the yielding of a CA-50 steel, it was adopted $\varepsilon_{\mathrm{cu}}=0,24 \%$.

The behavior of the stress-strain diagram of the concrete in the uniaxial compression was considered as parabolic, as shown in Figure 6. This behavior depends on the compression fracture energy $G_{c}$ and the cracking bandwidth $h$. Therefore, the compression fracture energy is given by Equation 5 :

$G_{c}=h f_{c} \frac{2}{3}\left(\varepsilon_{u}-\varepsilon_{c}\right)$

Where $G_{c}$ is given in $N m m / m^{2}$, $h$ is considered in $m m, f_{c}$ is the concrete compression strength in $\mathrm{MPa}, \varepsilon_{\mathrm{c}}$ is the peak deformation and $\varepsilon_{\mathrm{u}}$ is the final deformation of the concrete under uniaxial compression.

The biaxial behavior of the concrete was also considered in this model, considering the lateral confinement implemented in DIANA® 9.5 [10], based on the model proposed by Selby and Vecchio [21]. In addition, another important factor is the consideration of the compression strength behavior of concrete after the crack formation, as there is a reduction of the concrete resistance parallel to the cracks, as well as the compression stiffness. This phenomenon is better known as softening, which was based on the model implemented in DIANA $₫ 9.5$ [10], based on the Vecchio and Collins [24] model, shown in Figure 7. In this figure, the unit of cracks relative opening is strain/strain, since it is the relation between the crack opening deformation and a reference deformation that the authors, Vecchio and Collins [24], considered.

The concrete compression strength of a nodal region formed by the compression strut and the loop can be calculated through Equation 6, from item 6.5.4 of Eurocode 2: 2004.

$f_{c}=0,85 v^{\prime} f_{c d}$

Where $\mathrm{v}^{\prime}$ is a coefficient given by Equation 7 :

$v^{\prime}=1-\frac{f_{c}}{250}$.

The Eurocode 2: 2004, in item 6.5.2, presents a formulation to estimate the compression strength of cracked concrete, with cracks in the direction parallel to the compression application, given by Equation 8:

$f_{c f}=0,6 v^{\prime} f_{c d^{\prime}}$
Therefore, the reduction of concrete compression strength due to cracking is given by Equation 9:

$\operatorname{Red}=\frac{f_{c f}}{f_{c}}$.

After cracking, the concrete shear stiffness reduces, however, it still has the capacity to transmit shear stresses due to the aggregates interlock and the pin effect of reinforcement. The DIANA®-9.5 [10] models this reduction by applying a reducing coefficient on shear stiffness, according to Equation 10:

$G^{c r}=\beta G$.

Where $G^{\text {cr }}$ is the shear stiffness of the cracked concrete, $G$ is the shear stiffness of concrete without crack and $\beta$ is a shear retention coefficient, which varies from 0 to 1 . In the present work, the coefficient $\beta$ was taken as variable and proportional to the cracks opening. Assuming that all contact is lost once the crack length becomes greater than half the average diameter of aggregates, the shear retention can be calculated by Equation 11:

$\beta=1-\frac{2}{d_{\text {agg }}} \varepsilon_{n} h$.

Where $\mathrm{d}^{\text {agg }}$ is the average diameter of the aggregates, $\varepsilon_{n}$ is the strain normal to crack and $h$ is the cracking bandwidth. Since the maximum diameter of the aggregates $d_{\max }$ is $8 \mathrm{~mm}$, it was adopted, in the present work, a mean diameter of the aggregates of $5 \mathrm{~mm}$.

\subsection{Steel behavior}

The steel was considered with elastoplastic behavior, presenting the same behavior in tensile and in compression following the Von Mises criterion. The uniaxial behavior of the steel is shown in Figure 8.

\subsection{Numerical models validation}

The calibration was performed based on the curves that relate the

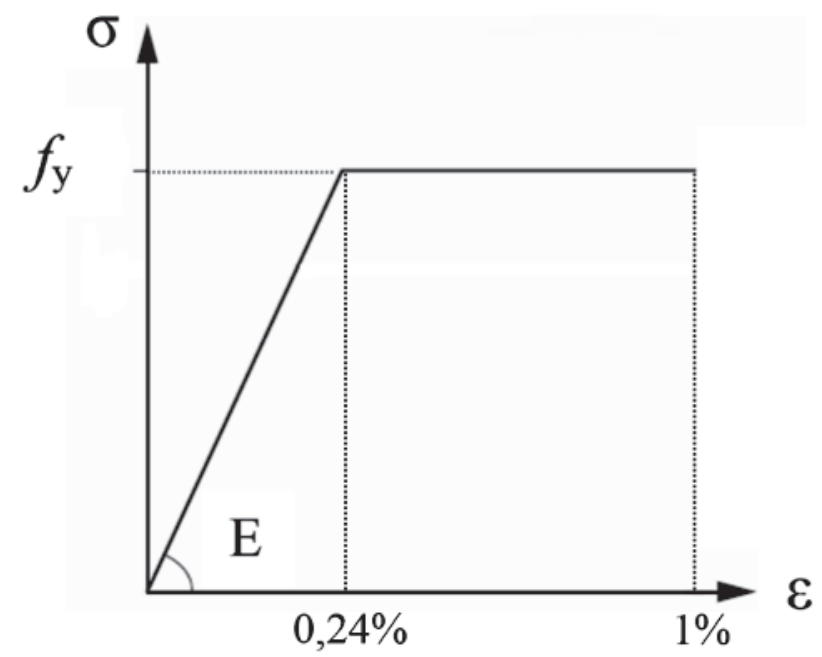

Figure 8

Steel behavior 
Table 2

Geometry, properties and results of the tested elements

\begin{tabular}{|c|c|c|c|c|c|c|c|}
\hline Element & $\mathrm{b}(\mathrm{mm})$ & $\mathrm{L}(\mathrm{mm})$ & $a(\mathrm{~mm})$ & $\mathrm{H}(\mathrm{mm})$ & $\phi_{\mathrm{T}}(\mathrm{mm})$ & $f_{y T}(M P a)$ & $\mathrm{N}_{\text {u.exp }}(\mathrm{A} / \mathrm{B})(\mathrm{kN})$ \\
\hline $10 A / B$ & 210 & 460 & 80 & 170 & 10 & 632.1 & $387.1 / 391.4$ \\
\hline $11 \mathrm{~A} / \mathrm{B}$ & $*$ & 380 & 60 & * & * & * & $459.6 / 419.6$ \\
\hline $12 \mathrm{~A} / \mathrm{B}$ & $*$ & 300 & 40 & * & * & * & $509.4 / 595.3$ \\
\hline $13 \mathrm{~A} / \mathrm{B}$ & 265 & 540 & 100 & 225 & * & * & $479.5 / 470.5$ \\
\hline $14 \mathrm{~A} / \mathrm{B}$ & 340 & $*$ & $*$ & 300 & $*$ & $*$ & $571.6 / 550.7$ \\
\hline $15 \mathrm{~A} / \mathrm{B}$ & 490 & $*$ & $*$ & 450 & * & * & $597.5 / 648.4$ \\
\hline
\end{tabular}

* Same value as the previous one.

force applied to the joint with the relative displacement between the joint interface and the precast concrete interface. It is noteworthy that the bars diameter is $20 \mathrm{~mm}$ and the yielding stress of the bars is $560.9 \mathrm{MPa}$.

The models whose parameters were calculated by the expressions of technical standards, as shown in the previous sections, were used as reference for the calibration. Six curves were used to validate the numerical models of the present work, which are related to the elements whose characteristics are shown in Table 2.

The letters $A$ and $B$, after the elements numbers, indicate that for each set of fixed parameters, two elements were made. In addition, $b$ is the joint thickness in $\mathrm{mm}, \mathrm{L}$ is the joint length in $\mathrm{mm}$, a is the distance between loops in $\mathrm{mm}, \mathrm{H}$ is the overlapping length in $\mathrm{mm}, \phi_{\mathrm{T}}$ is the diameter of the transverse bars in $\mathrm{mm}, \mathrm{f}_{\mathrm{yT}}$ is the yielding stress of the transverse bars in $\mathrm{MPa}$ and $\mathrm{N}_{\mathrm{u}, \mathrm{exp}}$ is the final tensile load of the elements in $\mathrm{kN}$. Thus, the calibration results are shown in Figure 9 and Table 3.

In the elements $10 \mathrm{~A}, 11 \mathrm{~A}$ and $12 \mathrm{~A}$, in which there was variation of the distance between loops, as this parameter decreases, the disparity between the curves increases. It occurs because this reduction of spacing is not accompanied by a mesh refinement, which reduces the amount of elements between the loops. It could be solved with a better refinement of this region, but the time of the simulations would impair the amount of analyses necessary in the study. Nevertheless, the maximum difference between the resistances of these models and those of the experimental ones is $16 \%$, which shows a good approximation. As for the models 13A, 14A and $15 \mathrm{~A}$, in which there is a variation of the longitudinal overlapping length, it is observed that as this parameter increases, there is a greater divergence between the stiffness of the numerical and experimental models, with a tendency to be smaller in these last ones. This is because in the numerical models it was considered

\section{Table 3}

Models ultimate loads

\begin{tabular}{cccc}
\hline \multirow{2}{*}{ Element } & \multicolumn{2}{c}{ Ultimate load (kN) } & Num/Exp \\
\cline { 2 - 3 } & $\begin{array}{c}\text { Numerical } \\
\text { (Num) }\end{array}$ & $\begin{array}{c}\text { Experimental } \\
\text { (Exp) }\end{array}$ & \\
\hline 10A & 399.6 & 389.3 & 1.03 \\
11A & 412.0 & 439.6 & 0.94 \\
12A & 464.0 & 552.4 & 0.84 \\
13A & 572.0 & 475.0 & 1.20 \\
14A & 708.0 & 561.2 & 1.26 \\
15A & 712.0 & 623.0 & 1.14 \\
\hline
\end{tabular}

perfect bond, that is, there is no slip between the straight part of the loop reinforcement and the surrounding concrete, which leads to a greater stiffness, increasing the disparity of behavior the greater the overlapping. For element $13 \mathrm{~A}$, although the resistances diverge, the behavior of the models is quite similar for the most part of the loading. In contrast, the models $14 \mathrm{~A}$ and $15 \mathrm{~A}$ present resistances very close to the yielding strength of the reinforcement, showing up as limits for design, as it will be explained later. Therefore, for values of overlapping lower than the one used in these last two models, the behavior of the numerical models approaches the behavior of the experimental models.

The values of the calibrated parameters are shown in Table 4. It is worth noting that most of the parameters were calibrated based on the values calculated by CEB 2010 [8].

Thus, the normative code CEB 2010 [8] and 1990 [7] can be considered for the calculation of concrete parameters when analyzing other types of concrete, since the values obtained by these standards are very close to the calibrated values, as can be seen in Table 4. In addition, the work of Hilsdorf and Brameshuber [14] can be used for the variables related to fracture energy.

\subsection{Parametric analysis}

With the calibrated models, a parametric analysis was performed. For this, the analyzed parameters were the spacing and the overlapping between loops, since the calibration was able to capture their variations reasonably well.

\section{Table 4}

Values of concrete parameters calibrated and calculated with CEB 2010

\begin{tabular}{cccc}
\hline Parameter & $\begin{array}{c}\text { Calculated } \\
\text { values }\end{array}$ & $\begin{array}{c}\text { Calibrated } \\
\text { values }\end{array}$ & Unit \\
\hline $\mathrm{E}_{\mathrm{ci}}$ & 43,032 & 40,000 & $\mathrm{MPa}$ \\
Poisson & 0.2 & 0.2 & - \\
$\mathrm{f}_{\mathrm{ct}}$ & 3.41 & 4.00 & $\mathrm{MPa}$ \\
$\mathrm{G}_{\mathrm{f}}$ & $0.051^{(1)}$ & 0.050 & $\mathrm{Nmm} / \mathrm{mm}^{2}$ \\
$\mathrm{~h}$ & $15.78^{(2)}$ & 15.00 & $\mathrm{~mm}$ \\
$\mathrm{f}_{\mathrm{c}}$ & 38.4 & 38.4 & $\mathrm{MPa}$ \\
$\mathrm{G}_{\mathrm{c}}$ & 1.38 & 1.00 & $\mathrm{Nmm} / \mathrm{mm}^{2}$ \\
$\mathrm{f}_{\mathrm{c}, \text { min }}$ & $0.71 \mathrm{f}_{\mathrm{c}}$ & $0.70 \mathrm{f}_{\mathrm{c}}$ & $\mathrm{MPa}$ \\
$\mathrm{d}_{\mathrm{agg}}$ & $5^{(3)}$ & 5 & $\mathrm{~mm}$ \\
\hline (1) Value calculated by Hilsdorf e Brameshuber (1991); \\
(2) Value calculated by CEB 1990; \\
(3) Value initially estimated.
\end{tabular}


The idea of the loops is to promote a splicing between bars so that a loop can transmit tensile stresses to the loop on the opposite side, as by the bond stress between steel and concrete, by the appearance of small struts between the straight parts of the loops, as by the radial stresses to the loop, forming, in this last case, a single and larger compression strut between the reinforcements.
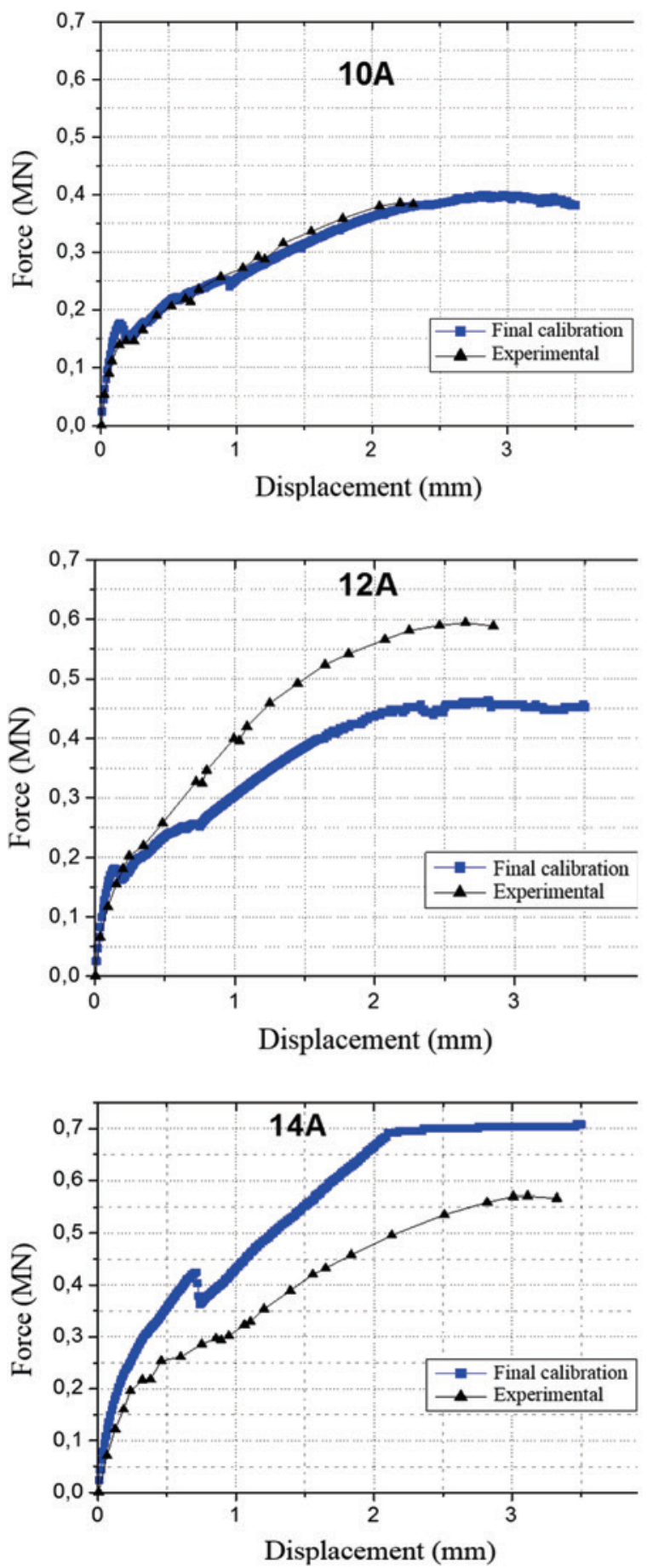

Figure 9

Final calibration of elements
Therefore, to optimize the stresses transmission by struts, the loops should be arranged as close as possible.

ABNT NBR 6118: 2014 [3], in the item 9.5.2.2, provides a formulation for calculating the overlapping length of straight bars in tensile whose free distance does not exceed 4 times the bar diameter, otherwise, it is necessary to increase the overlapping; in addition,
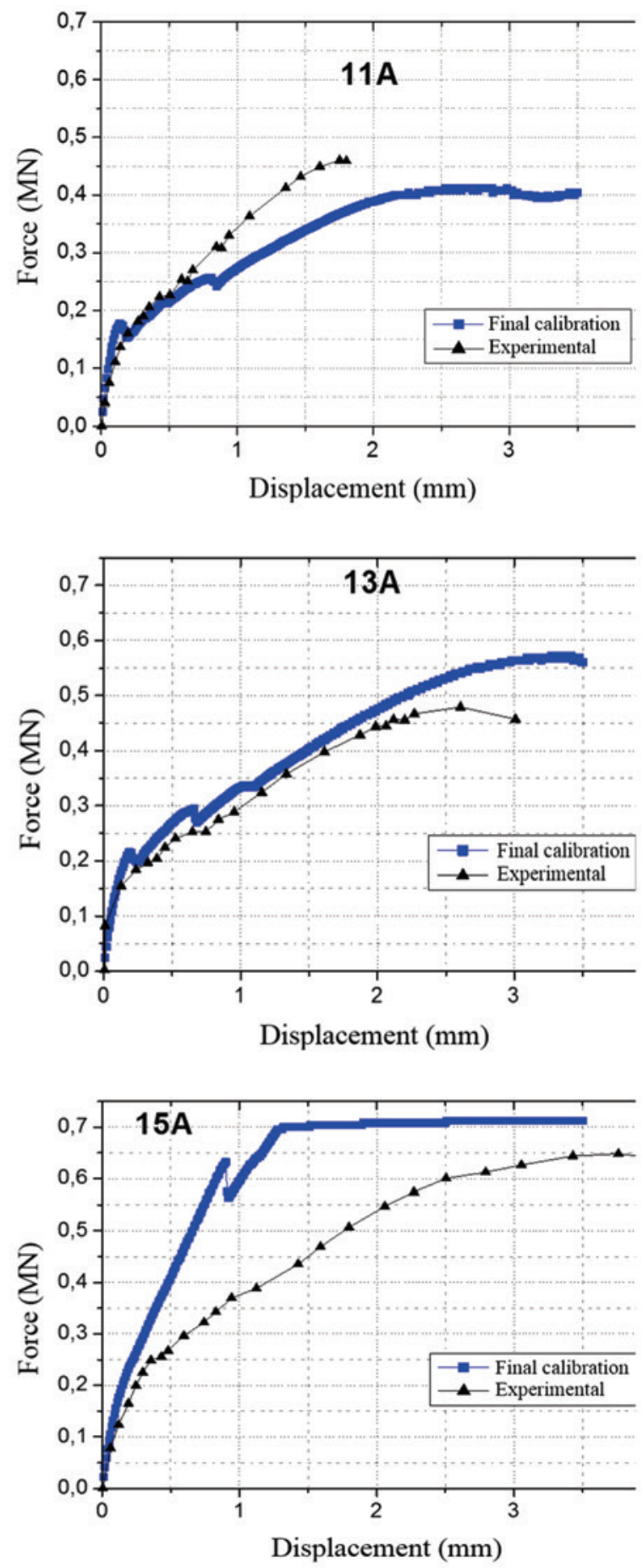


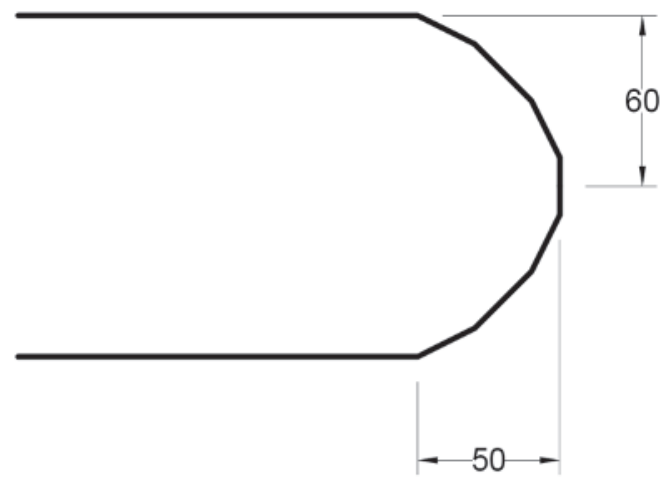

\section{Figure 10}

\section{Loop bend dimensions in $\mathrm{mm}$}

Bruggeling and Huyge [6] also recommend this value as the upper limit for loop joint. In this way, the ideal situation for the transmission of stress between overlapped straight bars is when the distance between them is less than or equal to 4 times their diameters. Therefore, considering only the transmission mechanism of straight bars, it is necessary to arrange the loops with a maximum free distance of $80 \mathrm{~mm}$, corresponding to a spacing of $100 \mathrm{~mm}$ between axes, considering the bar of $20 \mathrm{~mm}$ used in the models. Regarding the second mode of stress transmission, by the appearance of radial stresses to the loop and consequent formation of compression struts, the best arrangement of the overlapped bars is when they are in contact, that is, free distance 0 and spacing of $20 \mathrm{~mm}$. In this case, it is given a minimum inclination for the compression strut between the loops, being more requested by the joint, optimizing the transmission mechanism. Thus, the greater the spacing between the loops, the more they will behave as isolated loops, with no interaction between them. Therefore, for the parametric analysis, the spacing between loops was varied from $20 \mathrm{~mm}$ to $100 \mathrm{~mm}$, with intermediate values of 40,60 and $80 \mathrm{~mm}$. The loops must be overlapped in such a way that struts between them have the highest height as possible. For this occurrence, the loops must be overlapped at least in the value of their bend diameter, as recommended by Dragosavić et al. [11], who also recommend respecting the minimum value of 13 times the bars diameter, which in this case is $260 \mathrm{~mm}$. The models were calibrated based on the joints tested by Joergensen and Hoang [15], whose bend diameter of the loops is $110 \mathrm{~mm}$. In order to optimize the loop design by means of straight parts of beam members, which should have their nodes coincident with the nodes of the solid elements of the concrete, the loops of the models had to be different diameters in the directions of overlapping and perpendicular to it, of 100 and $120 \mathrm{~mm}$, respectively, as shown in Figure 10. Therefore, for the aforementioned verifications, a diameter of $100 \mathrm{~mm}$ was considered, constant during the analyses.

Analyzing the results of the calibration, it is noticed that failure occurred by yielding of the loops in the elements 14A and 15A, therefore, these elements were used as reference of upper limit for overlapping, because the failure load by yielding is known and can not be exceeded. In these elements, the overlappings are 300 and $450 \mathrm{~mm}$, respectively. Thus, considering a value around the mean of these, for the analysis in question, it was considered as a

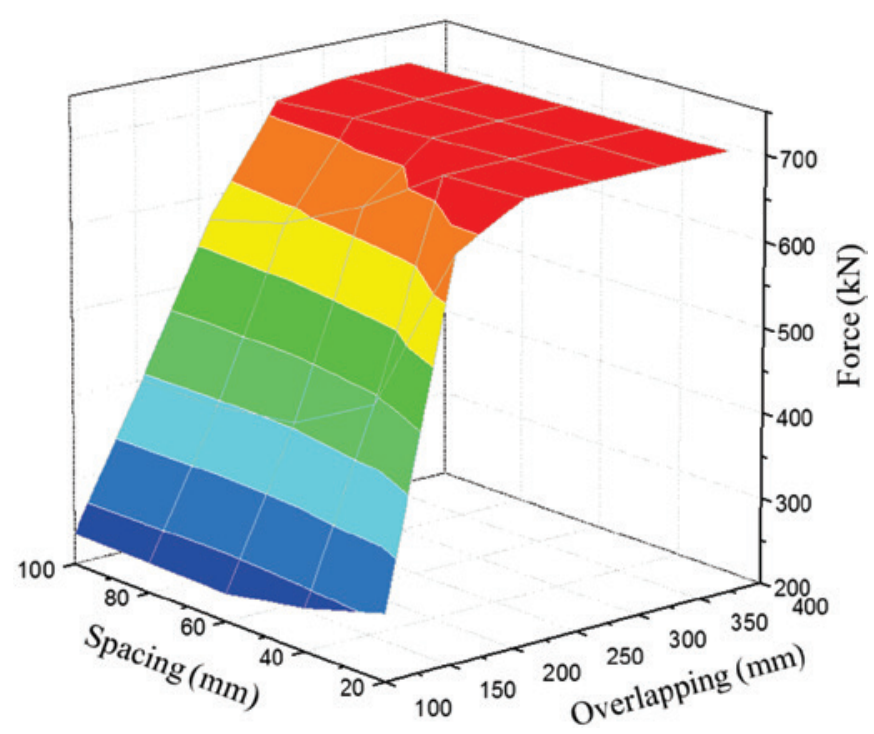

Figure 11

Representation of the parametric analysis results

maximum overlapping $370 \mathrm{~mm}$. Therefore, the overlapping values used in the analysis were: 100, 170, 225, 250, 300 and $370 \mathrm{~mm}$.

The results of the simulations are shown in Figure 11. It is noted that as the overlapping increases, the joint strength also increases. In addition, the surface has a well defined landing for overlapping values from $250 \mathrm{~mm}$. In this way, from this overlapping value, the failure of the joint tends to occur by yielding of the loops bars. It is also observed that there is a slight tendency to increase the load capacity of the joint the smaller the spacing between the loops.

In pull-out tests of straight steel bars in concrete, there are four ways of failure [1] (apud [20]):

- Pull-out: consists of sliding of the bar;

- Splitting: referring to the rupture of the concrete adjacent to the steel bar;

- Tensile: consists of the formation of cracks perpendicular to the direction of force application;

- Steel failure: relative to bar yielding.

The first three phenomena above lead to the rupture of only straight bars embedded in concrete, therefore, do not lead to the rupture of loop joints, because even if they occur, there will still be the contribution of the loop part in the resistance of the joint by the formation of compression struts. Thus, in loop joints, there are only two main modes of rupture: compression strut failure and loop yielding.

In Table 5, the values of the ultimate force for each geometry of the joint are shown, according to their overlapping and spacing between loops.

In this table, the combinations whose failure occurred by loop bars yielding are highlighted in red, with the remaining combinations relating to concrete failure of the compression struts. It is noteworthy that, in this case, the stress of $560.9 \mathrm{MPa}$ was considered as reference for the yielding, which corresponds to ultimate force of $704.85 \mathrm{kN}$.

Thus, for overlappings of 100 and $170 \mathrm{~mm}$, there is a tendency to occur rupture in the concrete for any spacing between loops; in 
Table 5

Ultimate force of the elements, in $\mathrm{kN}$

\begin{tabular}{cccccc}
\hline \multirow{2}{*}{$\begin{array}{c}\text { Overlapping } \\
(\mathbf{m m})\end{array}$} & $\mathbf{2 0}$ & $\mathbf{4 0}$ & $\mathbf{6 0}$ & $\mathbf{8 0}$ & $\mathbf{1 0 0}$ \\
\cline { 2 - 6 } & 278.1 & 249.6 & 232.9 & 234.6 & 235.9 \\
100 & 666.0 & 464.0 & 412.0 & 399.6 & 400.0 \\
170 & 711.6 & 708.8 & 645.2 & 596.4 & 572.0 \\
225 & 712.4 & 710.4 & 707.2 & 703.2 & 695.6 \\
250 & 713.2 & 712.4 & 710.8 & 708.4 & 708.0 \\
300 & 713.6 & 713.2 & 712.0 & 710.8 & 709.6 \\
370 & & & & & \\
\hline
\end{tabular}

contrast, for overlappings above $300 \mathrm{~mm}$, there is a tendency to occur rupture by bars yielding for any spacing between loops.

Figure 12 shows the graphs Applied force on the bar $x$ Displacement between interfaces, relative to the joints with variation of spacing and constant overlapping. In the graphics legend, the first value refers to the overlapping, and the second value refers to the spacing between loops.

In this figure, it is noticed that for the overlapping of $100 \mathrm{~mm}$, there is practically no change in the joint behavior, in addition, the load capacity of these joints is much lower than the others. In this way, this overlapping is insufficient for the transmission of stress by the compression struts formed between the loops. For the $170 \mathrm{~mm}$ overlapping, there is a significant increase in the ultimate force, especially for the spacing of $20 \mathrm{~mm}$, which increases about $140 \%$ in relation to the $100 \mathrm{~mm}$ overlapping, reaching a value close to that corresponding to the bar yielding stress. From the overlapping of $225 \mathrm{~mm}$, it begins to occur rupture by the bars yielding. It is also observed that from the $300 \mathrm{~mm}$ overlapping, the only difference in the behavior of the joints is related to the joint stiffness, which is larger the smaller the spacing, with the rupture by bars yielding for any spacing between loops. Furthermore, from this overlapping, the curved portion of the loops becomes less and less requested, with a tendency of the bars to work only as straight bars embedded in the concrete. Finally, it is noticed that there is not much

\section{Table 6}

Ultimate force of the elements, in $\mathrm{kN}$

\begin{tabular}{|c|c|c|c|}
\hline Analytical model & Type of joint & Principle & Formulation of the joint load capacity \\
\hline $\mathrm{HaO}[13]$ & 2 to 1 & $\begin{array}{l}\text { Strut and } \\
\text { tie model }\end{array}$ & $N_{u}=\frac{270 h H f_{c}^{0,21}}{\sqrt{H^{2}+a^{2}}}$ \\
\hline Araújo et al. [2] & 1 to 1 & $\begin{array}{l}\text { Strut and } \\
\text { tie model }\end{array}$ & $\begin{array}{c}N_{u}=(D+2 \phi) w_{t} f_{c n} \frac{H}{\sqrt{s^{2}+H^{2}}} \\
w_{t}=\frac{(0.6894-0.0022 D) s}{\lambda} \\
\lambda=0.014 s+0.553 \geq 0.86 \\
f_{c n}=0,85 f_{c}\end{array}$ \\
\hline
\end{tabular}

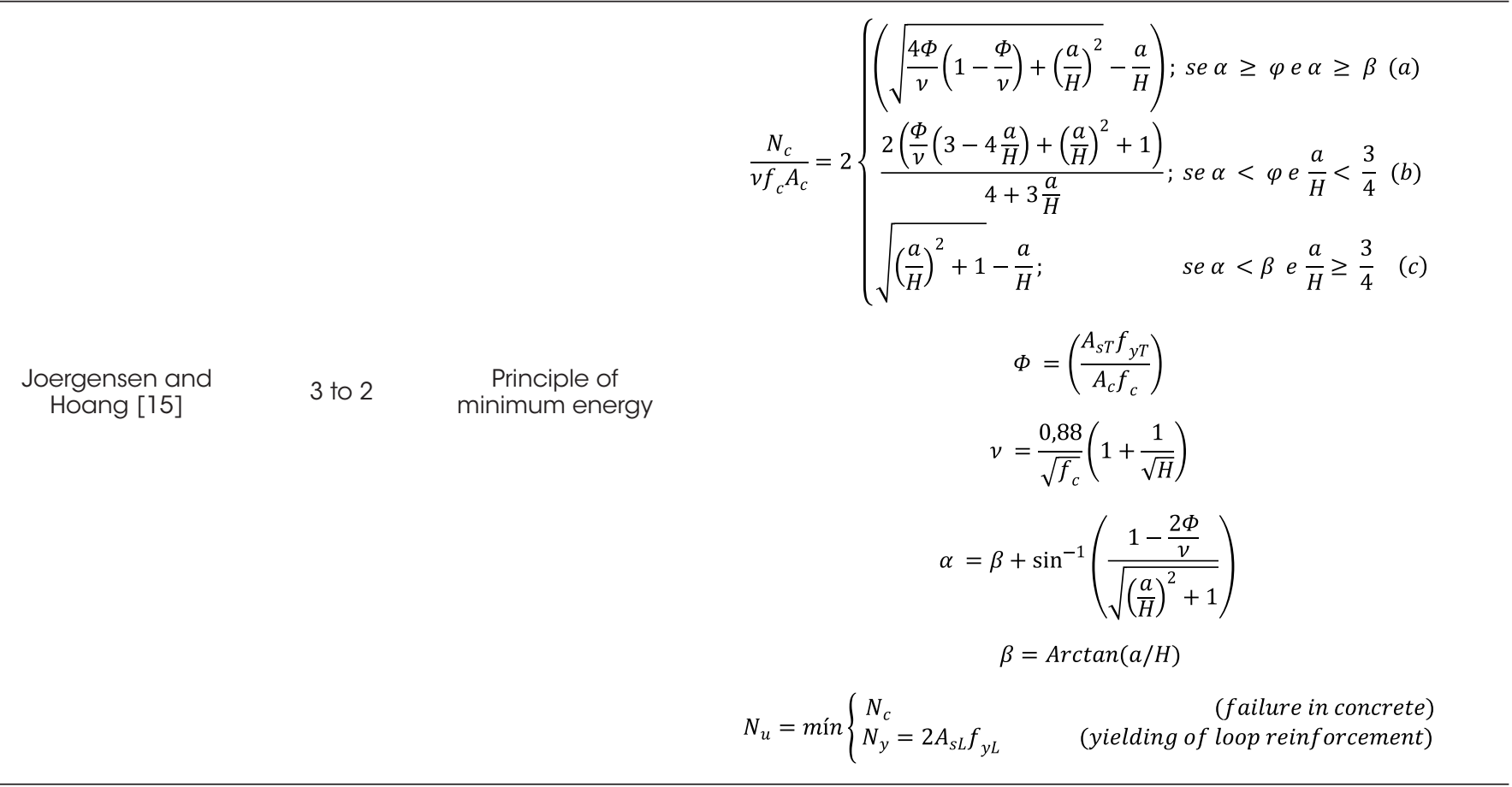


difference in the behavior of the joints with spacing of 80 and $100 \mathrm{~mm}$, therefore, from these spacings, there is a greater tendency of the loops to work separately, that is, it reduces
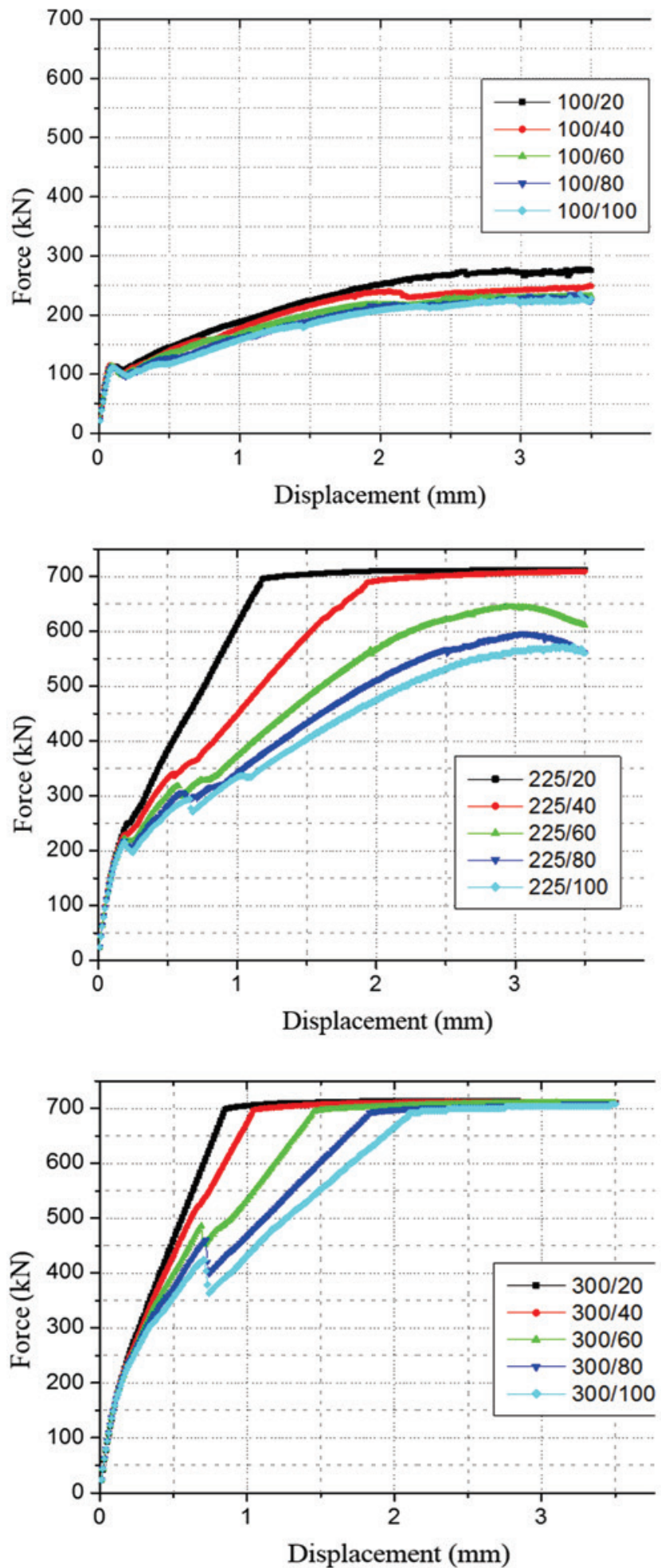

Figure 12

Graphics of the joints with constant overlapping the tendency of compression struts formation between the loops. In Figure 13, the force $x$ displacement graphs of the joints with variation of overlapping and constant spacing are shown. For
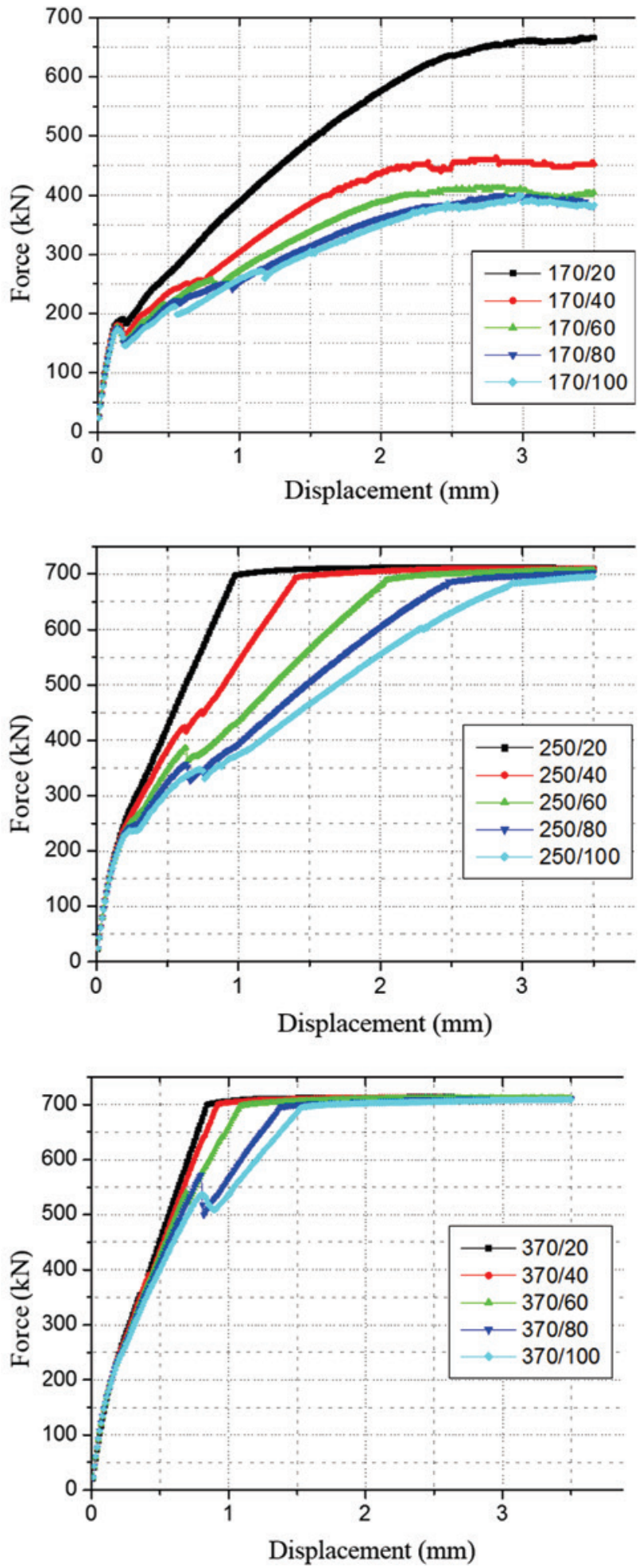
Legend of the overlapping lenghts, in mm
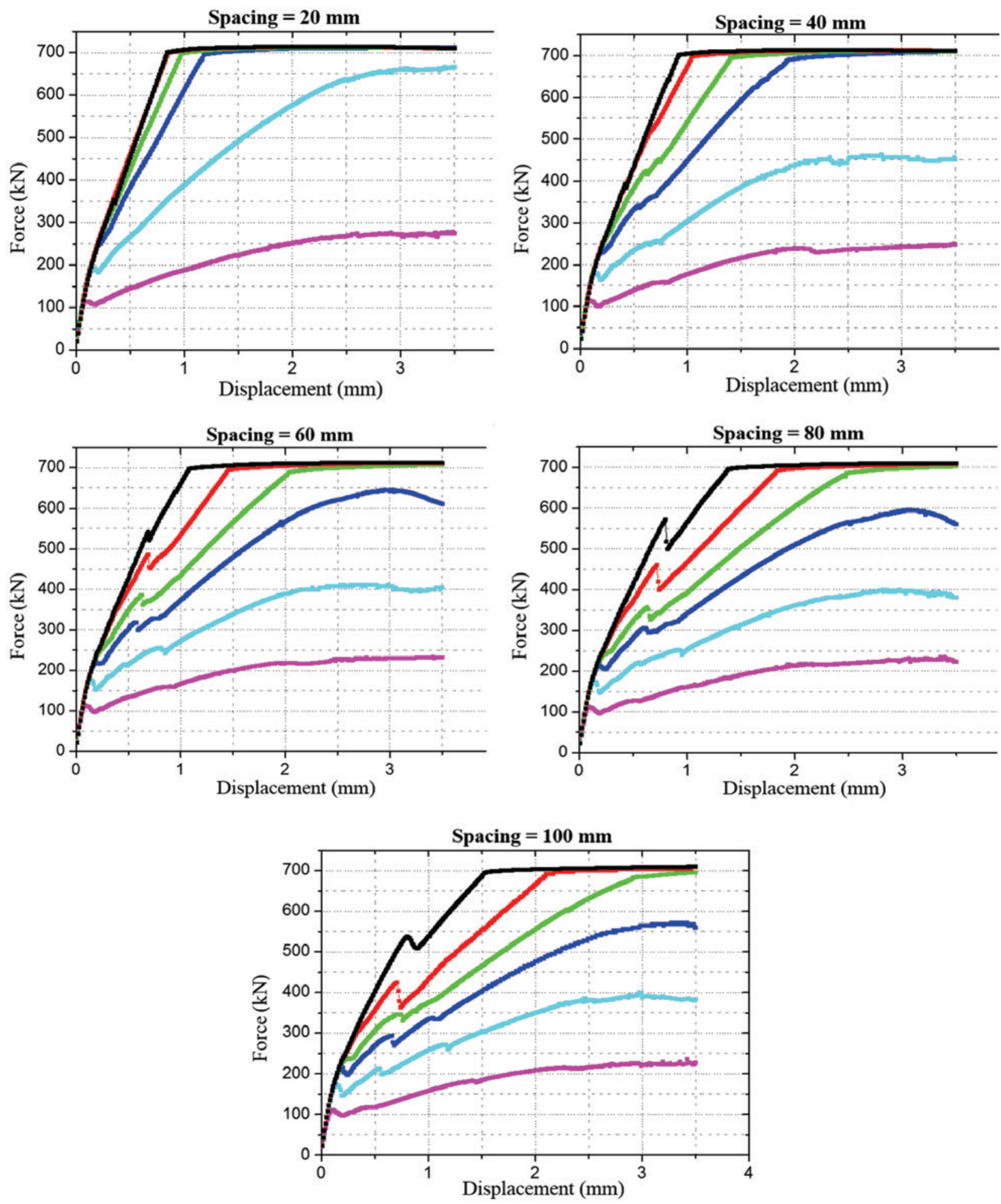

Figure 13

Graphics of the joints with constant spacing 
the spacing between loops of $20 \mathrm{~mm}$, that is to say, when the overlapped bars are in contact, with overlapping over or equal to $300 \mathrm{~mm}$, the joints behavior under tensile is quite similar to each other. This fact can be observed in the graphics corresponding to the overlappings of 300 and $370 \mathrm{~mm}$, whose curves are superimposed in most points. Thus, as the overlapping length increases, the joints tend to have the same behavior, represented by the curve corresponding to the joint with spacing of $20 \mathrm{~mm}$ and overlapping of $300 \mathrm{~mm}$. This shows that this overlapping is already sufficient to overlap straight bars, because for values from this, the rupture tends to occur by bars yielding. It is also noticed that as the spacing increases, the load capacity and stiffness of the joint decrease.

Finally, the smaller the spacing between loops and the greater the overlapping between them, the greater the load capacity of the joint studied. It is also noteworthy that the loop can cause concrete splitting if there is not enough concrete covering around it, capable of promoting an appropriate confinement of the reinforcement. However, this type of rupture was not evaluated in this study.

\subsection{Analytical models of loop joints under tensile}

For loop joint under tensile, the analytical models obtained from the literature are described in Table 6, where there are the models of Hao [13], Araújo et al. [2] and Joergensen and Hoang [15]. In the formulation of Hao [13], $\mathrm{N}_{u}$ is the ultimate force in the joint, $\mathrm{h}$ is the height of the concrete element, $\mathrm{H}$ is the overlapping length of the loops, $f_{c}$ is the compression concrete strength and $a$ is the spacing between loops.

In the formulations of Araújo et al. [2], $\mathrm{N}_{\mathrm{u}}$ is the ultimate force in the joint, $\mathrm{D}$ is the internal diameter of the loop, $\varphi$ is the bar diameter, $w_{t}$ is the effective thickness of the inclined strut, $f_{c n}$ is the compressive strength of the strut, $\mathrm{H}$ is the loop overlapping length, $\mathrm{s}$ is the internal spacing between loops, $\lambda$ is a coefficient related to the softening effect of concrete and $f_{c}$ is the compression concrete strength. In the formulations of Joergensen and Hoang [15], $N_{c}$ is the joint strength considering only the failure of the compression strut between loops, $v$ is a correction factor that takes into account the fact that concrete is not a perfectly plastic material, $f_{c}$ is the compression concrete strength, $A_{c}$ is the concrete area between loops

Table 7

Comparison of the results with the analytical models

\begin{tabular}{|c|c|c|c|c|c|c|c|c|}
\hline Spacing & Overlapping & Model & Hao & Araújo & Joergensen & $\mathrm{M} / \mathrm{H}$ & M/A & $\mathrm{M} / \mathrm{J}$ \\
\hline \multirow{6}{*}{20} & 100 & 278.1 & 227.8 & 199.8 & 398.7 & 1.2 & 1.4 & 0.70 \\
\hline & 170 & 666.0 & 230.8 & 202.4 & 590.5 & 2.9 & 3.3 & 1.13 \\
\hline & 225 & 704.8 & 231.4 & 203.0 & 704.8 & 3.0 & 3.5 & 1.00 \\
\hline & 250 & 704.8 & 231.6 & 203.1 & 704.8 & 3.0 & 3.5 & 1.00 \\
\hline & 300 & 704.8 & 231.8 & 203.3 & 704.8 & 3.0 & 3.5 & 1.00 \\
\hline & 370 & 704.8 & 232.0 & 203.5 & 704.8 & 3.0 & 3.5 & 1.00 \\
\hline \multirow{6}{*}{40} & 100 & 249.6 & 215.7 & 292.4 & 312.9 & 1.2 & 0.9 & 0.80 \\
\hline & 170 & 464.0 & 226.2 & 306.5 & 517.4 & 2.1 & 1.5 & 0.90 \\
\hline & 225 & 704.8 & 228.8 & 310.0 & 632.8 & 3.1 & 2.3 & 1.11 \\
\hline & 250 & 704.8 & 229.4 & 310.9 & 677.9 & 3.1 & 2.3 & 1.04 \\
\hline & 300 & 704.8 & 230.3 & 312.1 & 704.8 & 3.1 & 2.3 & 1.00 \\
\hline & 370 & 704.8 & 231.0 & 313.1 & 704.8 & 3.1 & 2.3 & 1.00 \\
\hline \multirow{6}{*}{60} & 100 & 232.9 & 199.2 & 323.6 & 257.5 & 1.2 & 0.7 & 0.90 \\
\hline & 170 & 412.0 & 219.1 & 355.9 & 455.4 & 1.9 & 1.2 & 0.90 \\
\hline & 225 & 645.2 & 224.5 & 364.7 & 568.8 & 2.9 & 1.8 & 1.13 \\
\hline & 250 & 704.8 & 225.9 & 367.0 & 613.6 & 3.1 & 1.9 & 1.15 \\
\hline & 300 & 704.8 & 227.8 & 370.1 & 694.2 & 3.1 & 1.9 & 1.02 \\
\hline & 370 & 704.8 & 229.3 & 372.5 & 704.8 & 3.1 & 1.9 & 1.00 \\
\hline \multirow{6}{*}{80} & 100 & 234.6 & 181.4 & 327.2 & 218.4 & 1.3 & 0.7 & 1.07 \\
\hline & 170 & 399.6 & 210.2 & 379.1 & 403.2 & 1.9 & 1.1 & 0.99 \\
\hline & 225 & 596.4 & 218.9 & 394.8 & 513.1 & 2.7 & 1.5 & 1.16 \\
\hline & 250 & 703.2 & 221.3 & 399.0 & 557.0 & 3.2 & 1.8 & 1.26 \\
\hline & 300 & 704.8 & 224.5 & 404.8 & 636.6 & 3.1 & 1.7 & 1.11 \\
\hline & 370 & 704.8 & 227.1 & 409.5 & 704.8 & 3.1 & 1.7 & 1.00 \\
\hline \multirow{6}{*}{100} & 100 & 235.9 & 164.3 & 317.2 & 188.1 & 1.4 & 0.7 & 1.25 \\
\hline & 170 & 400.0 & 200.3 & 386.7 & 359.4 & 2.0 & 1.0 & 1.11 \\
\hline & 225 & 572.0 & 212.3 & 410.0 & 464.8 & 2.7 & 1.4 & 1.23 \\
\hline & 250 & 695.6 & 215.7 & 416.5 & 507.4 & 3.2 & 1.7 & 1.37 \\
\hline & 300 & 708.0 & 220.4 & 425.6 & 585.3 & 3.2 & 1.7 & 1.21 \\
\hline & 370 & 704.8 & 224.3 & 433.1 & 681.6 & 3.1 & 1.6 & 1.03 \\
\hline
\end{tabular}




\section{Table 8}

Average, standard deviation and coefficient of variation of the relations

\begin{tabular}{cccc} 
& $\mathbf{M} / \mathbf{H}$ & $\mathbf{M} / \mathbf{A}$ & $\mathbf{M} / \mathbf{J}$ \\
\hline Average & 2,60 & 1,87 & 1,05 \\
Standard deviation & 0,73 & 0,84 & 0,14 \\
Coefficient of variation & 0,28 & 0,45 & 0,13 \\
\hline
\end{tabular}

projected on the loop plane, $\Phi$ is the mechanical rate of transversal reinforcement, $\mathrm{a}$ is the spacing between loops, $\mathrm{H}$ is the overlapping between loops, $\alpha$ is the inclination of the relative displacement on the plane of rupture with respect to this plane, $\phi$ is the concrete friction angle, considered equal to Arctan (3/4) for concrete of normal resistance, $\beta$ is the inclination of the rupture plane with respect to the loop plane, $A_{s T}$ is the steel area transverse to the loop plane, $\mathrm{f}_{\mathrm{yT}}$ is the yielding stress of the transversal bars, $\mathrm{N}_{\mathrm{y}}$ is the joint resistance considering only the loop yielding, $A_{\mathrm{sL}}$ is the total steel area of one loop and $f_{y L}$ is the yielding stress of the loop bar.

The formulations proposed by Hao [13] and Araújo et al. [2] are quite similar, this is due to the fact that both are based on the strut and tie model. The difference between the models is in consideration of the cross sectional area of the compression struts. With respect to the height of the compression strut, Hao [13] considers equal to the joint height, while Araújo et al. [2] consider equal to the loop height, that is, $D+2 \varphi$. As for the strut thickness $w_{t}$, which is the parameter of greatest divergence between the authors, Hao [13] establishes the calculation based only on the concrete compressive strength, while Araújo et al. [2] define equations based on the loop diameter and the spacing between them.

Although the models proposed by the previous authors have presented satisfactory results in relation to the respective experimental results, they do not take into account some of the parameters that define the joint, such as the transversal reinforcement ratio and its yielding stress. In contrast, the model proposed by Joergensen and Hoang [15] is based on the principle of minimum energy, considering all parameters of influence of joint. Thus, the model proposed by Joergensen and Hoang [15] is presented as the most complete to represent the behavior of loop joint.

\subsection{Comparison of the numerical results with the analytical models}

The results obtained in the parametric analysis were compared with the joint strengths calculated by the analytical models proposed by Hao [13], Araújo et al. [2] and Joergensen and Hoang [15].

The models developed by Hao [13] and Araújo et al. [2] refer to loop joint 2 to 1 and 1 to 1 , respectively. Thus, it was made an extrapolation of the formulations to calculate the resistance of loop joint 3 to 2 , used in the present work.

The loading capacities of the joints calculated by the above formulations are shown in Table 7. As also, they are shown the relationships between the values of the Model and $\mathrm{HaO}(\mathrm{M} / \mathrm{H})$, the Model and Araújo (M / A) and the Model and Joergensen (M / J). In addition, Table 8 shows the averages of these relationships, their respective standard deviations and coefficients of variation.
It is noteworthy that for the calculation of these three parameters, the values of resistance above the force corresponding to the bars yielding were replaced by the value of this force, that is, 704.85 $\mathrm{kN}$, since this value corresponds to the maximum value of the joint rupture, as explained in item 3.6.

As described in item 3.7, the models proposed by Hao [13] and Araújo et al. [2] are similar to each other, which consider the strut and tie model. The only difference between the models is the consideration of the cross sectional area of the compression struts. To calculate the strut thickness, the first author presents a formulation dependent only on the concrete strength and the other authors have a formulation dependent only on the loops bend diameter and the spacing between them. It is noticed a large divergence between the values obtained by means of the numerical model and the values calculated using the formulations of these authors, whose averages of the ratios between them is 2.6 for the Hao model [13] and 1.87 for the model of Araújo et al. [2], besides standard deviations of 0.73 and 0.84 and coefficients of variation of 0.28 and 0.45 , respectively.

In the Hao model [13], the overlapping variation between loops practically does not change the joint resistance, presenting a slight increase with the increase of this parameter, and the increase of the spacing between loops reduces the joint resistance, although it is not a significant reduction.

In the model of Araújo et al. [2], the increase in the overlapping also changes little the joint capacity, increasing it. In contrast, increasing the spacing between loops leads to an increase in the joint strength.

In relation to the spacing, the two models diverge from each other, because in the Hao model [13], the spacing is inversely proportional to the joint capacity, in contrast, in the model of Araújo et al. [2], the increase of this variable leads to a greater thickness of the compression strut, increasing, in turn, the joint resistance. On the other hand, with respect to the variation of the overlapping between loops, the formulations show agreement between them.

The aforementioned models consider that the stress transfer between loops occurs only by the formation of compression struts between them, disregarding the bond stress along the straight part of the bars. Therefore, there is a great disparity between the results with the numerical models and with the formulations proposed by Hao [13] and Araújo et al. [2].

The results with the numerical models present excellent agreement with the formulation developed by Joergensen and Hoang [15], with the mean value of the values ration of 1.05 , standard deviation of 0.14 and coefficient of variation of 0.13 .

Therefore, the models proposed by Hao [13] and Araújo et al. [2] were not appropriate to estimate the load capacity of the joints studied in the present work, being specific to their respective works. On the other hand, the model developed by Joergensen and Hoang [15] is the best one to calculate the loading capacity of 3 to 2 loop joints submitted to tensile.

\section{Conclusions}

The present work presented a study about loop bar splicing in reinforced concrete joints under tensile. For this, the software DIANA $₫$ was used, with which, initially, a calibration of numerical models 
was performed based on the work of Joergensen and Hoang [15], varying the parameters whose values were unknown. With the calibrated models, a parametric analysis was performed, varying the overlapping and spacing between loops.

\subsection{Overlapping}

The overlapping values studied ranged from $100 \mathrm{~mm}$ to $370 \mathrm{~mm}$. When observing the results of the models, it is noticed that from an overlapping of $300 \mathrm{~mm}$, all the joints had rupture by yielding of the loops bars for any value of spacing between them, in addition, the overlapping of $100 \mathrm{~mm}$, value of the loop bend diameter, proved to be insufficient for the formation of significant compression struts.

Most of the investigated authors recommend as the minimum value for overlapping the value of the loop bend diameter, besides this value, Dragosavić et al. [11] also recommend respecting the minimum value of 13 times the bars diameter, which for the case under study is $260 \mathrm{~mm}$. Thus, in order to optimize the joint strength and ensure that the rupture occurs by yielding of the loop bars, it is recommended to use overlapping values between 11 and 15 times the loop bars diameter, depending on the spacing between them. In addition, it is necessary to consider as minimum overlapping the loop bend diameter.

\subsection{Spacing}

The spacing values studied varied from $20 \mathrm{~mm}$ to $100 \mathrm{~mm}$, with the first value corresponding to the contact between the loops bars, since in the present work, bars with a diameter of $20 \mathrm{~mm}$ are used. The results showed that the highest strengths were achieved when $20 \mathrm{~mm}$ spacing was used, because, with this value, the compression strut has the lowest possible inclination, thus maximizing the stress on it. It is also noticed that the models with spacing of $80 \mathrm{~mm}$ and $100 \mathrm{~mm}$ showed very similar behaviors, indicating a tendency that, from these values, the loops work separately, which reduces the joint efficiency. In this way, it is recommended to overlap the loops bars so that they stay in contact and when it is not possible, the limit of 3 times the diameter of these bars must be respected.

\subsection{Analytical models}

When it was used the analytical models proposed by Hao [13] and Araújo et al. [2] modified for 3 to 2 joints, the results presented very large disparities with respect to the numerical results of the parametric analysis, presenting divergent behaviors in many cases. Therefore, these models should not be extrapolated to joints with other geometries different from those studied by the respective authors, being specific to the joints of each work. On the other hand, in relation to the results obtained with the Joergensen and Hoang model [15], there was excellent agreement with the numerical models results, with the mean value of the joints resistances ratio of 1.05 , standard deviation of 0.14 and coefficient of variation of $13 \%$. Therefore, this formulation can be used to estimate the load capacity of 3 to 2 loop joints, subjected to tensile and having any overlapping length and spacing between loops.

\section{Acknowledgments}

To the School of Engineering of São Carlos for giving me the opportunity to contribute a little more with the Master Program in Structures and for providing me this excellent formation. To the National Council of Scientific and Technological Development (CNPq) for the master scholarship.

\section{References}

[1] AL-JAHDALI, F. A.; WAFA, F. F.; SHIHATA, S. A. Development length for straight deformed bars in high-strength concrete. ACI Special Publication, v.149, outubro 1994.

[2] (Júlio, Branco e Silva, 2004)ARAÚJO, D. D. L.; CURADO, M. C.; RODRIGUES, P. F. Loop connection with fibre-reinforced precast concrete components in tension. Engineering Structures, v. 72, n. 0, p. 140-151, maio 2014.

[3] ASSOCIAÇÃO BRASILEIRA DE NORMAS TÉCNICAS. NBR 6118: Projeto de estruturas de concreto - Procedimento. Rio de Janeiro, 2014.

[4] ASSOCIAÇÃO BRASILEIRA DE NORMAS TÉCNICAS. NBR 9062: Projeto e execução de estruturas de concreto pré-moldado. Rio de Janeiro, 2006.

[5] BRITISH STANDARDS INSTITUTION. BS 8110: Structural use of concrete. Part 1: Code of practice for design and construction. BSI, Londres, 1997.

[6] BRUGGELING, A. S. G. ; HUYGE, G. F. Prefabrication with concrete. Rotterdam: A.A. Balkema; 1991.

[7] CEB-FIP MODEL CODE 1990 - final draft. Bulletin D'Information, n. 203-205. Thomas Telford, Londres, 1991.

[8] CEB-FIP MODEL CODE 2010 - first complete draft. Bulletin 55, v. 1, Alemanha 2010.

[9] DIANA. DIANA Finite Element Analysis. User's manual release 9.5. Material Library. TNO DIANA, Delft, Netherland, 2014.

[10] DIANA. DIANA Finite Element Analysis. User's manual release 9.5. Element Library. TNO DIANA, Delft, Netherland, 2014.

[11] DRAGOSAVIĆ, M.; VAN DEN BEUKEL, A.; GIJSBERS, F. B. J. Loop connections between precast concrete components loaded in bending. Heron, v. 20, n. 3, 1975.

[12] EUROPEAN STANDARD EN. Eurocode 2: Design of concrete structures - Part 1: General rules and rules for buildings. Comité Européen de Normalisation, Brussels, 225 p., 2004.

[13] HAO, J. Structural behaviour of precast component joints with loop connection. 2004. 395 p. Tese (Doutorado em Engenharia Civil) - Departamento de Engenharia Civil, Universidade Nacional de Singapura, Singapura, 2004.

[14] HILSDORF, H. K.; BRAMESHUBER, W. Code-type formulation of fracture mechanics concepts for concrete. International Journal of Fracture, v. 51, n. 1, p. 61-72, 1991.

[15] JOERGENSEN, H. B.; HOANG, L. C. Tests and limit analysis of loop connections between precast concrete elements loaded in tension. Engineering Structures, v. 52, n. 0, p. 558569, abr. 2013.

[16] JÚLIO, E. N. B. S.; BRANCO, F. A. B.; SILVA, V. D. Concrete-to-concrete bond strength. Influence of the roughness of the substrate surface. Construction and Building Materials, v. 18, n. 9, p. 675-681, jun. 2004. 
[17] LEONHARDT, F.; WALTER, R.; DIETERLE, H. Versuche zur Ermittlung der Tragfähigkeit von Zugschlaufenstößen (Em inglês: Tests for evaluating the tensile strength of loop joints). Deutscher Ausschuss für Stahlbeton, Bulletin $n^{\circ} 226$, p. 1-22, 1973.

[18] MATTOCK, A. H. Effectiveness of loop anchorages for reinforcement in precast concrete members. $\mathrm{PCl}$ journal, v. 39 , n. 6, p. $54-68,1994$

[19] ROSENTHAL, I.; SHIMONI, J. Bending behavior of a double-loop connection between precast concrete slabs. Concrete International, v. 6, n. 11, p. 30-34, 1984.

[20] SANTANA, I. V. Estudo da influência das fibras metálicas no comportamento da aderência entre barras de aço e concretos de diferentes classes de resistência. 2014. 246 p. Dissertação (Mestrado em Engenharia Civil) - Escola de Engenharia de São Carlos, Universidade de São Paulo, São Carlos, 2014.

[21] SELBY, R. G.; VECCHIO, F. J. Three-dimensional Constitutive Relations for Reinforced Concrete. Universidade de Toronto, Departemento de Engenharia Civil, Toronto, Canada, 1993.

[22] VASCONCELOS, T. D. L. Estudo numérico do comportamento de emendas de barras por meio de laço em juntas de estruturas de concreto armado. 2017. 123 p. Dissertação (Mestrado em Engenharia Civil, Estruturas) - Escola de Engenharia de São Carlos, Universidade de São Paulo, São Carlos, 2017.

[23] VECCHIO, F. J., COLLINS, M. P. The modified compression field theory for reinforced concrete elements subjected to shear. ACl Journal, v. 83 , n. 22, p. 219-231, março-abril de 1986.

[24] VECCHIO, F. J., COLLINS, M. P. Compression response of cracked reinforced concrete. Journal of Structural Engineering, v. 119, n. 12, p. 3590-3610, dezembro de 1993.

[25] VILLALBA, S. et al. New structural joint by rebar looping applied to segmental bridge construction: Fatigue strength tests. Journal of Bridge Engineering, v. 18, n. 11, p. 11741188, 2013. 